\title{
Differences in how Nurses and Public Health Nurses Perceive Registered Dietitians and Dietitians in Japan
}

\author{
Shin Yamaoka*, Tatsuya Koyama \\ Aomori University of Health and Welfare \\ *Corresponding Author: Shin Yamaoka, Aomori University of Health and Welfare, E-mail: \\ aomori.yamaoka@gmail.com
}

\begin{abstract}
Introduction: There are qualifications in Japan for the occupations of registered dietitians and dietitians, such as scientific knowledge of nutrition and diet. However, there is little examination of how other professionals working with them on medical teams perceive the differences between registered dietitians and dietitians. Therefore, in this study, we conducted self-administered questionnaires of public health nurses and nurses to investigate the perceptions of registered dietitians and dietitians among multiple occupations.

Methods: In the self-administered questionnaire we asked whether they had worked with a registered dietitian or dietitian, as well as what they knew about the differences between registered dietitians and dietitians.

Results and Discussion: First, 91\% of the respondents had worked with registered dietitians or dietitians, reflecting the fact that in Japan, registered dietitians or dieticians and nurses or public health nurses work together. We also found that 45\% of the participants answered that they did not know the differences between registered dietitians and dietitians. If the results of other studies are compared, the level of recognition of registered dietitians or dietitians among Japanese medical professionals will be clarified.
\end{abstract}

Keywords: Registered dietitian, Dietitian, nurse, Public health nurse, Multidisciplinary team

Abbreviation: Registered dietitian, RD; Public health nurse, PHN

\section{INTRODUCTION}

In Japan, experts of nutrition and diet hold one of two qualifications, registered dietitian (RD) and dietitian. A RD is a person who, using the title Registered Dietitian under license from the Minister of Health, Labor and Welfare, is engaged in the service of providing nutritional guidance necessary for medical treatment of the sick and injured, nutritional guidance for maintaining and promoting health which is specific to the physical condition, nutritional condition and the like of each individual which requires highly specialized knowledge and skills, and who is engaged in providing food service management at food service facilities which provide meals to a large number of specific people on a continuous basis, of which said management requires special consideration to be taken depending on the physical condition and nutritional condition of users and how such facilities are used, and providing guidance and instruction necessary for improving nutrition at such facilities. ${ }^{1)}$. On the other hand, a dietitian is a person a person who is engaged in the service of providing nutritional guidance using the title Dietitian under license from a prefectural governor [1].

In current medical care, for example, physicians on nutrition support teams often include RDs and nurses [2], and in Japan, in addition to RDs, nutrition support teams include physicians, nurses, public health nurses (PHN), and other medical professionals [2-4]. Therefore, there may be opportunities for RDs and dietitians to demonstrate their abilities and presence to their fellow group members. However, little is known about how group members working with RDs or dietitians perceive the differences between them. If the perception of differences between the RD and dietitian by practitioners in other occupations is clarified, the results will allow us to better understand the job descriptions of RDs or dietitians in medical care where multidisciplinary teams are needed, thereby allowing us to improve approaches to medical care involving the cooperation of many 
occupations. Therefore, in this study, we conducted a self-written questionnaire for members of the occupations involved, such as nurses and public health nurses, to examine their perception of RDs and dietitians when working with them on multidisciplinary teams in order to clarify what is necessary for an approach to medical care in which occupations work well together.

\section{Materials And Methods}

In November 2019, we conducted the survey in a questionnaire for nurses and PHNs in Aomori. We asked on the questionnaire whether they had ever worked with a RD or dietitian, as well as what they know about the differences between RDs and dietitians.

\section{RESULTS AND DISCUSSION}

The 11 respondents comprised 4 nurses and 7 PHNs. Of the 11, 10 (91\%) have worked with RDs or dietitians. Table 1 shows the results regarding respondents' knowledge about the differences between RDs and dietitians.

Table1: Results of questionnaire

\begin{tabular}{|c|c|c|}
\hline $\begin{array}{l}\text { Occupat } \\
\text { ion }\end{array}$ & $\begin{array}{l}\text { Have you worked with registered } \\
\text { dietitians or dietitians? }\end{array}$ & $\begin{array}{l}\text { Recognition of difference between registered dietitians and } \\
\text { dietitians }\end{array}$ \\
\hline Nurse & No & I don't know the difference. \\
\hline Nurse & Yes & $\begin{array}{l}\text { Is it a registered dietitian who can provide more advanced } \\
\text { guidance than a dietitian? Even in medical fees, a registered } \\
\text { dietitian is required at hospitals, etc. }\end{array}$ \\
\hline Nurse & Yes & $\begin{array}{l}\text { If there is a national qualification, a hospital or facility } \\
\text { arrangement, it can be added. I don't know the details. }\end{array}$ \\
\hline Nurse & Yes & $\begin{array}{l}\text { Become a dietitian, gain a few years of experience, and become } \\
\text { a registered dietitian }\end{array}$ \\
\hline PHN & Yes & I'm not sure \\
\hline PHN & Yes & Don't know \\
\hline PHN & Yes & $\begin{array}{l}\text { Whether or not you have a national qualification. A registered } \\
\text { dietitian is qualified. A dietitian can graduate from a specialized } \\
\text { school. Only a dietitian can teach people who are sick. }\end{array}$ \\
\hline PHN & Yes & A registered dietitian is in a better position. \\
\hline PHN & Yes & $\begin{array}{l}\text { I can hardly tell you about the difference between national } \\
\text { qualifications or the education required for the exam. }\end{array}$ \\
\hline PHN & Yes & $\begin{array}{l}\text { A registered dietitian can provide pathological knowledge and } \\
\text { health guidance. It is a national qualification. }\end{array}$ \\
\hline PHN & Yes & $\begin{array}{l}\text { A registered dietitian provides nutrition guidance, education, } \\
\text { and so on. }\end{array}$ \\
\hline
\end{tabular}

The field of medical care and other areas in Japan today, issues of multi-disciplinary cooperation are being addressed [5]. As this study found that $91 \%$ of the respondents had worked together with a RD or dietitian, there is a possibility that most RDs or dietitians, nurses, and public health nurses in Japan work together. Also, 4 of the 11 respondents (36\%) stated that dietitians are involved in nutritional guidance and medical treatment, while $5(45 \%)$ stated that they did not know the difference. Our results imply that about half of nurses or PHNs do not know the difference between RDs and dietitians. However, few studies have asked nurses, PHNs, and other medical professionals about the difference between RDs and dietitians.

Currently little is known about how other other professionals recognize $\mathrm{RD}$ and dietitian qualified people in Japan [2-6]. However, it is necessary for the members of multidisciplinary teams to understand each other's occupations when cooperating in rendering medical care. Therefore, the results of this study reveal the perceptions of RDs and dietitians by nurses and PHNs. In the future, we will continue this research by increasing the number of respondents to better elucidate the differences between RDs and dietitians in the perceptions of medical professionals, as well as clarifying the approaches to medical care of various occupations cooperating with RDs and dietitians.

\section{CONClusion}

In this study, we investigated the differences between RDs and dietitians as perceived by members of other medical occupations, such as nurses and public health nurses, in Japan and examined their perceptions of the differences between RDs and nutritionists in other 
occupations. We found that in Japan, most nurses and public health nurses work with RDs or dietitians. However, few studies have examined whether nurses, public health nurses, and other medical professionals recognize the differences between registered dietitians and dietitians. Therefore, repeating this study with more respondents would serve to further clarify medical professionals' perceptions of RDs and dietitians and might show what else is needed when RDs and dietitians work with members of other occupations.

\section{ACKNOWLEDGMENTS}

We express our deepest appreciation to the participants for their cooperation throughout the study. We have no potential conflicts of interest to declare.

\section{REFERENCES}

[1] Saitou C, Yoshioka Y, with an administrative dietitian - history, system, current situation (introduction of education, the research field of special feature new establishment subject [Aomori Prefectural health university] nourishment subject). An Aomori Prefectural health university magazine. 10(2), 233-235 (2009).
[2] Uchida T, Yokoyama M, Yoshimura K, Hitomi,E, Examination of the factors necessary for nutrition care in the ward by cooperation among occupations. Yamaguchi Prefectural University academic information. 12, 141-160 (2019).

[3] Shimizu M, Tanaka K, Kuroki S, Ikenoshima M, Hibino M: To plan continuation of approach ... care conference for the care conference regularization with the multi-type of job and the improvement of contents; Takayama Red Cross hospital bulletin. 38, 13-16 (2015)

[4] Suizu K, Oota Y, Tanaka S: Reality of dietary planning in long-term health care facilities. Yamaguchi Prefectural University academic information. 10, 47-59 (2017)

[5] Fujiwara K, Nishimura K, Tamaura Y, Kawasaki Y, Junko Suzuki J, Kamata Y, Miyuki Hara M, Kouji Yoshizawa K, Goto C, Hosoe M, Sakai M: Case report on cooperation between a hospital nutrition care station and a community comprehensive support center by registered dietitians.Japan Dietetic Association magazine. 60(9), 515-519 (2017)

[6] Yamashita Y, Murata M, Okada M, Chitose S, Esaka M, Fujii K, Mizui F: Study on evaluation of dietitian education at Hiroshima Bunka Gakuen two-year College by employers of graduates. 44, 31-38 (2011).

Citation: Shin Yamaoka, Tatsuya Koyama. Differences in how Nurses and Public Health Nurses Perceive Registered Dietitians and Dietitians in Japan. ARC Journal of Nutrition and Growth. 2019; 5(2):17-19. DOI: dx.doi.org/ 10.20431/2455-2550. 050204.

Copyright: () 2019 Authors. This is an open-access article distributed under the terms of the Creative Commons Attribution License, which permits unrestricted use, distribution, and reproduction in any medium, provided the original author and source are credited. 